\title{
Impact force analysis using the B-spline material point method
}

\author{
Vay Siu Lo ${ }^{1,2, *}$, Nha Thanh Nguyen ${ }^{1,2}$, Minh Ngoc Nguyen ${ }^{1,2}$, Thien Tich Truong ${ }^{1,2, *}$
}

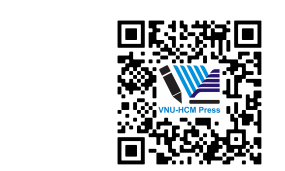

Use your smartphone to scan this QR code and download this article

${ }^{1}$ Department of Engineering Mechanics, Faculty of Applied Sciences, Ho Chi Minh City University of Technology, Vietnam.

${ }^{2}$ Vietnam National University Ho Chi Minh City, Vietnam.

Correspondence

Vay Siu Lo, Department of Engineering Mechanics, Faculty of Applied Sciences, Ho Chi Minh City University of

Technology, Vietnam.

Vietnam National University Ho Chi Minh City, Vietnam.

Email: losiuvay@hcmut.edu.vn

Correspondence

Thien Tich Truong, Department of Engineering Mechanics, Faculty of Applied Sciences, Ho Chi Minh City University of Technology, Vietnam.

Vietnam National University Ho Chi Minh City, Vietnam.

Email: ttruong@hcmut.edu.vn

\section{History}

- Received: 18-11-2020

- Accepted: 11-3-2021

- Published: 30-3-2021

DOI : 10.32508/stdjet.v4i1.794

\section{Check for updates}

\section{Copyright}

(C) VNU-HCM Press. This is an openaccess article distributed under the terms of the Creative Commons Attribution 4.0 International license.

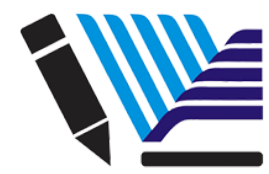

VNU-HCM Press

\begin{abstract}
In the MPM algorithm, all the particles are formulated in a single-valued velocity field hence the non-slip contact can be satisfied without any contact treatment. However, in some impact and penetration problems, the non-slip contact condition is not appropriate and may even yield unreasonable results, so it is important to overcome this drawback by using a contact algorithm in the MPM. In this paper, the variation of contact force with respect to time caused by the impact is investigated. The MPM using the Lagrange basis function, so causing the cell-crossing phenomenon when a particle moves from one cell to another. The essence of this phenomenon is due to the discontinuity of the gradient of the linear basis function. The accuracy of the results is therefore also affected. The high order B-spline MPM is used in this study to overcome the cell-crossing error. The BSMPM uses higher-order B-spline functions to make sure the derivatives of the shape functions are continuous, so that alleviate the error. The algorithm of MPM and BSMPM has some differences in defining the computational grid. Hence, the original contact algorithm in MPM needs to be modified to be suitable in order to use in the BSMPM. The purpose of this study is to construct a suitable contact algorithm for BSMPM and then use it to investigate the contact force caused by impact. Some numerical examples are presented in this paper, the impact of two circular elastic disks and the impact of a soft circular disk into a stiffer rectangular block. All the results of contact force obtained from this study are compared with finite element results and perform a good agreement, the energy conservation is also considered.
\end{abstract}

Key words: BSMPM, contact algorithm, contact force, impact, MPM

\section{INTRODUCTION}

The material point method (MPM) was first developed in 1994 by Sulsky and his colleagues ${ }^{1}$. Over 25 years of development, the number of researchers working on it is increasing more and more. Many universities and institutes around the world have investigated this method, such as Delft University of Technology ${ }^{2}$, Stuttgart University ${ }^{3}$, Cardiff University ${ }^{4}$.

The MPM uses both Lagrangian description and Eulerian description ${ }^{1}$ so it has the advantages of both descriptions. MPM has been widely used to simulate high-velocity problems such as impact ${ }^{5}$ and explosion ${ }^{6}$, large deformation problems $\mathrm{s}^{7}$, fracture ${ }^{8}$ and also Fluid-Structure Interaction ${ }^{9}$.

However, the original MPM has a major shortcoming that affects the simulation results. When a particle moves across a cell boundary, it will lead to numerical errors due to the discontinuity of the gradient of the basis functions ${ }^{1}$. This is called the "cellcrossing error" ${ }^{2}$. In order to alleviate the effect of this phenomenon, different methods were proposed. Bardenhagen et al. proposed the Generalized Interpolation Material Point method (GIMP) ${ }^{10}$. Variants in the GIMP branch were also introduced, Steffen et al. proposed the Uniform GIMP (uGIMP) ${ }^{11}$, the Convected Particle Domain Interpolation (CPDI) was introduced by Sadeghirad et al. ${ }^{12}$. Zhang et al. modified the gradient of shape functions to enhance the MPM ${ }^{13}$. Steffen et al. introduced the Bspline MPM (BSMPM) ${ }^{14}$ by applying the high order B-spline function into MPM algorithm. The BSMPM is then further improved by Tielen et al. ${ }^{2}$, Gan et al. ${ }^{15}$, Wobbes et al. ${ }^{16}$.

In the MPM algorithm, a single-valued velocity field is used for all particles so the non-slip contact condition between two bodies is satisfied automatically ${ }^{1}$. However, in some impact and penetration problems, the non-slip contact condition is not appropriate, so it is important to develop a contact algorithm for MPM. York et al. proposed a simple contact algorithm for MPM $^{17}$, Bardenhagen et al. proposed an algorithm for multi-velocity field ${ }^{18}$, and many other improvements can be mentioned as Hu and Chen ${ }^{19}$, Huang et al. ${ }^{20}$, Nairn ${ }^{21}$, Ma et al. ${ }^{22}$.

This study using the BSMPM to mitigate the cellcrossing error. The BSMPM and MPM have differences in computational grid definition. Therefore, the contact algorithm for MPM cannot be directly applied to BSMPM. In this paper, the contact algorithm is 
modified to a suitable form to the BSMPM. The implementation steps are mentioned in Section 2.3. The contact force obtained from impact of two elastic objects are compared with the result from FEM, a slight difference between FEM and MPM (and BSMPM) results is observed and explained in Section 3.

\section{METHODOLOGY}

\section{B-spline basis functions}

Considering a vector containing non-decrease values $\Xi=\left\{\xi_{1}, \xi_{2}, \ldots, \xi_{n+d}, \xi_{n+d+1}\right\}$, where $n$ is the number of basis functions, $\mathrm{d}$ is the polynomial order. Each value in this vector is called knot and satisfies the relation $\xi_{1} \leq \xi_{2} \leq \ldots \leq \xi_{n+d} \leq \xi_{n+d+1}$. Vector $\Xi$ contains a sequence of knots is called the $k n o t$ vector ${ }^{2}$. The B-spline basis functions are constructed by a knot vector. A uniform knot vector is a knot vector containing equally distributed knots, e.g $\Xi=\{0,1,2,3,4,5\}$ is a uniform knot vector. From the relation of the knots sequence, one notices that the value of adjacent knots can be repeated, if $\xi_{1}$ and $\xi_{n+d+1}$ are repeated $d+1$ times, it is an open knot vector $^{2}$, e.g $\Xi=\{0,0,0,1,2,3,4,5,5,5\}$ is an open knot vector with $n=7$ and $d=2$.

The $i$-th B-spline basis function of order $d\left(N_{i, d}\right)$ is defined by using Cox-de Boor recursion formula ${ }^{15}$. Firsly, the zeroth order $(d=0)$ basis function must be defined

$$
N_{i, 0}=\left\{\begin{array}{c}
1 \text { if } \xi_{i} \leq \xi \leq \xi_{i+1} \\
0 \text { otherwise }
\end{array}\right.
$$

the non-zero intervals $\left[\xi_{i}, \xi_{i+1}\right)$ are called knot spans $^{2}$. After obtaining $N_{i, 0}$, higher order $(d \geq i)$ basis functions are defined as the formula below

$$
\begin{aligned}
& N_{i, d}(\xi)=\frac{\xi-\xi_{i}}{\xi_{i+d}-\xi_{i}} N_{i, d-1}(\xi) \\
& +\frac{\xi_{i+d+1}-\xi}{\xi_{i+d+1}-\xi_{i+1}} N_{i+1, d-1}(\xi)
\end{aligned}
$$

in which the fraction $0 / 0$ is assumed to be zero. Figure 1 shows the high order B-spline basis functions $(d=2, d=3)$.

The derivatives of basis function $N_{i, d}\{\xi\}$ are calculated as following

$$
\begin{gathered}
\frac{d N_{i, d}(\xi)}{d \xi}=\frac{d}{\xi_{i+d}-\xi_{i}} N_{i, d-1}(\xi) \\
-\frac{d}{\xi_{i+d+1}-\xi_{i+1}} N_{i+1, d-1}(\xi)
\end{gathered}
$$

In two dimensions, the bivariate B-spline functions can be built from the tensor product of the univariate ones ${ }^{8}$

$$
N_{i, j}(\xi, \eta)=N_{i, p}(\xi) N_{j, q}(\eta)
$$

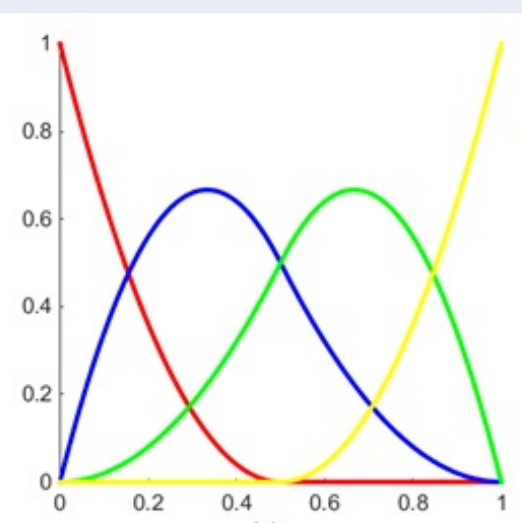

(a)

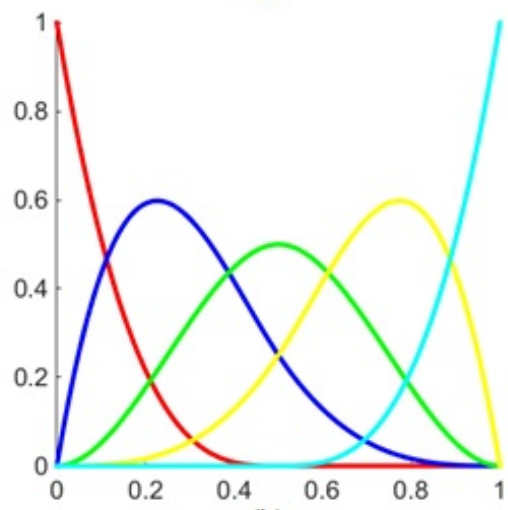

(b)

Figure 1: (a) Quadratic B-spline basis functions ( $d$ $=2$ ) built from an open uniform knot vector $\Xi=$ $\{0,0,0,0.5,1,1,1\}$ and (b) Cubic B-spline basis functions $(d=3)$ defined by $\Xi=\{0,0,0,0.5,1,1,1\}$

where $p$ and $q$ are the order of the univariate basis function.

Two important properties of B-spline basis functions are: they are non-negative for all $\xi$ and the functions have the partition of unity property, i.e. $\sum_{i=1}^{n} N_{i, d}=$ $1^{15}$.

\section{B-spline Material Point Method}

In 2D BSMPM, the computational domain is discretized by a parametric grid ${ }^{15}$. This grid is defined by two open knot vectors on two orthogonal directions $\Xi=\left\{\xi_{1}, \xi_{2}, \ldots, \xi_{n+p}, \xi_{n+p+1}\right\}$ and $I=$ $\left\{\eta_{1}, \eta_{2}, \ldots, \eta_{m+q}, \eta_{m+q+1}\right\}$ as shown in Figure 2 . The numbers of basis functions in $\xi$ and $\eta$ direction are $n$ and $m$, respectively, so the total number of basis functions is $n \times m$. A tensor product grid with the total of $n \times m$ nodes is constructed as shown in Figure 3, each node of this grid corresponds to one B-spline basis function as defined in Eq. (4). For example, the node with the position $(1,3)$ on the grid corresponds 
to the basis function $N_{1,3}(\xi, \eta)=N_{1, p}(\xi) N_{3, q}(\eta)$. All the nodes on this tensor product grid are defined as control points in BSMPM (the same role for grid node in MPM), and in practice these control points are arbitrary distribution ${ }^{15}$.

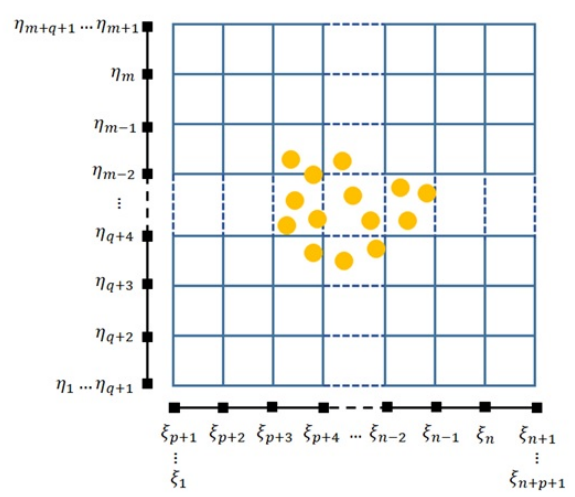

Figure 2: A 2D parametric grid constructed from two open knot vectors $\Xi$ and I

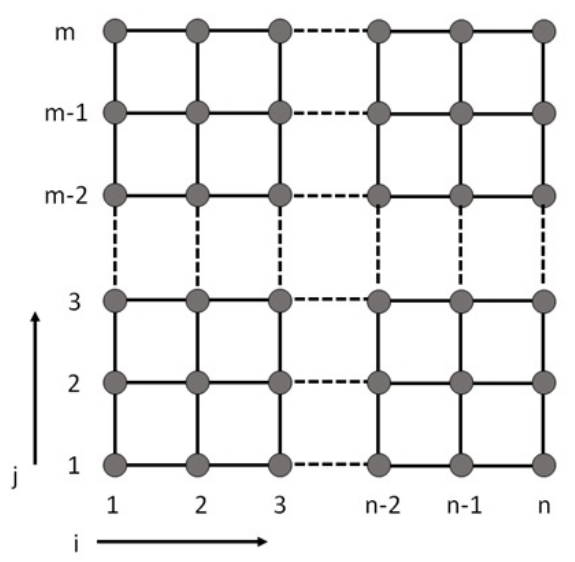

Figure 3: A tensor product grid containing $n \times m$ nodes (control points)

As shown in Figure 4 a second order (quadratic) BSMPM grid. The cell is made from 3 knot spans in $x$ direction and 2 knot spans in $y$ direction, so the number of knots in knot vectors are 4 and 3, respectively. The number of control points in $x$ direction is 3 (knot spans) +2 (order) $=5$ and in $y$ direction is equal 4 . These control points play the role of grid nodes in the original MPM, the knots from knot vectors are only used for creating a computational grid. At can be seen in Figure 4, each cell has 9 control points, for example, the lower-left cell related to $[1,2,3,6,7,8,11,12,13]$.
The figure also shows a particle located in the uppermiddle cell, so this particle is mapped to $[7,8,9,12$, $13,14,17,18,19]$.

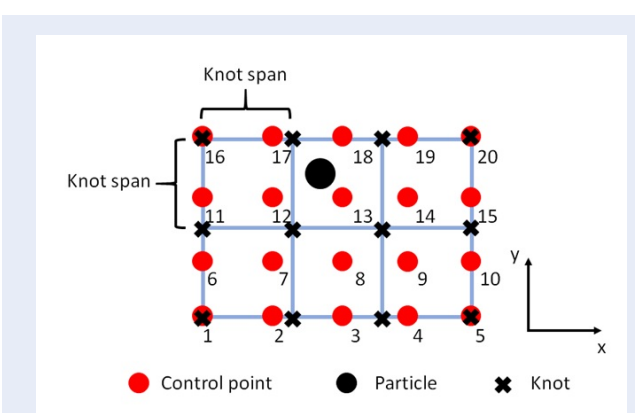

Figure 4: A quadratic ( $d=2)$ BSMPM grid

Unlike the original MPM, the particles in BSMPM are considered in the whole discretized domain, instead of a specific cell, as shows in the equation below ${ }^{23}$

$$
\begin{aligned}
& \xi=\frac{x-x_{\min }}{x_{\max }-x_{\min }}, \\
& \eta=\frac{y-y_{\min }}{y_{\max }-y_{\min }}
\end{aligned}
$$

where $\left(x_{\min }, y_{\min }\right)$ is the lower-left control point and $\left(x_{\max }, y_{\max }\right)$ is the upper-right control point. This is the formula for mapping between the parameter space to the physical space.

The derivatives of the B-spline basis functions are given as below ${ }^{23}$

$$
\left[\frac{\partial N}{\partial x}\right]=\left[\frac{\partial N}{\partial \xi}\right]\left[\begin{array}{ll}
\frac{\partial \xi}{\partial x} & \frac{\partial \xi}{\partial y} \\
\frac{\partial \eta}{\partial x} & \frac{\partial \eta}{\partial y}
\end{array}\right]=\left[\frac{\partial N}{\partial \xi}\right] J_{\xi}^{-1}
$$

where $\mathbf{J}$ is the Jacobian matrix and defined by

$$
J=\left[\begin{array}{ll}
\frac{\partial x}{\partial \xi} & \frac{\partial x}{\partial \eta} \\
\frac{\partial y}{\partial \xi} & \frac{\partial y}{\partial \eta}
\end{array}\right]
$$

and the components are computed as

$$
\frac{\partial x}{\partial \xi}=\sum_{A=1} P_{A} \frac{\partial N(\xi)}{\partial \xi}
$$

where $\mathbf{P}$ denotes the coordinates of the control points and $\mathrm{A}$ is the global index of control point ${ }^{23}$.

In the BSMPM, for convenient the knot vector for an interval $[0, L]$ is defined by $\Xi=\{0, \ldots, 0, \triangle x, 2 \triangle x, \ldots, L-\triangle x, L, \ldots, L\}$, where $\triangle x$ denotes the length of knot $\operatorname{span}^{15}$. And note that the knot vector must be normalized before a parametric grid is created, so the 
knot vector is rewritten as the following form $\Xi^{\prime}=\left\{0, \ldots, \frac{\triangle x}{L}, \frac{2 \triangle x}{L}, \ldots, \frac{L-\triangle x}{L}, 1, \ldots, 1\right\}$, this is also a difference in the parameter space between B-spline basis functions and other functions. The control points are arbitrary distributed and they are in the physical coordinate $(x, y)$.

\section{Contact algorithm}

This section presents the algorithm proposed by Bardenhagen et al. ${ }^{18}$ and makes appropriate modification to apply into the BSMPM.

When two bodies are approaching each other, there is a region where they have some of the same control points. These control points are viewed as the contact points, the contact algorithm is applied on these points only.

In the contact region, the following equation ${ }^{18}$ is used as a condition to check if two bodies are in contact or release

$$
\left(v_{I}^{i, t}-v_{I}^{c m}\right) \cdot n_{I}^{i}=\left\{\begin{array}{l}
\geq 0 \text { contact } \\
<0 \text { release }
\end{array}\right.
$$

where $i$ denotes the $i$-th body in the computational domain, $v_{I}^{c m}$ is the center-of-mass velocity ${ }^{23}$ of the control point $I$-th for each pair in contact

$$
v_{I}^{c m}=\frac{p_{I}^{1, t+\triangle t}+p_{I}^{2, t+\triangle t}}{m_{I}^{1, t}+m_{I}^{2, t}}
$$

In Eq. (9), $n_{I}^{i}$ is the normal vector of control point $I-t h$ of body $i$-th and computed as following steps.

Firstly, the density $\rho_{c}$ for each cell in contact state is computed as below ${ }^{23}$

$$
\rho_{c}^{i}=\frac{1}{V_{e}} \sum_{p=1}^{n_{p}} m_{p}^{i} S^{2}\left(x_{p}^{i}-x_{c}^{i}\right)
$$

where $V_{e}$ is volume of cell $e$-th, $x_{c}$ is the center of cell $e$-th. Remember that in the BSMPM each cell is made of knot spans (see Figure 4).

In $1 \mathrm{D}$, the function $S^{x}(x)$ is given by the following definition $^{23}$

$$
=\left\{\begin{array}{c}
S^{x}(x) \\
-\frac{1}{2 h^{2}} x^{2}+\frac{3}{2 h} x+\frac{9}{8},-\frac{3}{2 h} \leq x \leq-\frac{1}{2 h} \\
\frac{1}{h^{2}} x^{2}+\frac{3}{4},-\frac{1}{2 h} \leq x \leq \frac{1}{2 h} \\
\text { 0, otherwise }
\end{array}\right.
$$

The function $S^{2}(x, y)$ in Eq. (11) is obtained by multiplying two 1D functions $S^{2}(x, y)=S^{x}(x) S^{y}(y)$. Finally, the normal vector of control point $I$-th is obtained $^{23}$

$$
n_{I}^{i}=\sum_{c} G_{I}\left(x_{c}^{i}\right) \rho_{c}^{i}
$$

where $G_{I}$ is the derivatives of the B-spline basis functions.

Before applying into Eq. (9) for checking contact, the normal vector in Eq. (13) must be normalized ${ }^{23}$

$$
n_{I}^{i}=\frac{n_{I}^{i}}{\left\|n_{I}^{i}\right\|}
$$

The implementation of contact algorithm into the BSMPM algorithm can be summarized as following steps:

Step 1: Mapping data from particles to control points 1. Compute the mass of $I-t h$ control point from the i-th body: $m_{I}^{i, t}=\sum_{p} N_{I}\left(x_{p}^{i, t}\right) M_{p}^{i}$

2. Compute the momentum of $I$-th control point from the $i$-th body: $p_{I}^{i, t}=\sum_{p} N_{I}\left(x_{p}^{i, t}\right)(M v)_{p}^{i}$

3. Compute external force at control point $I$ from $i$-th body: $f_{I}^{\text {ext }, i, t}$

4. Compute internal force at control point $I$ from $i$-th body: $f_{I}^{i n t, i, t}=-\sum_{p} V_{p}^{i, t} \sigma_{p}^{i, t} \nabla N_{I}\left(x_{p}^{i, t}\right)$

5. Compute the total force at control point $I: f_{I}^{i, t}=$ $f_{I}^{\text {ext }, i, t}+f_{I}^{\text {int }, i, t}$

Step 2: Update the control point momentums: $p_{I}^{i, t+\triangle t}=p_{I}^{i, t}+f_{I}^{i, t} \triangle t$

Step 3: Imposed boundary conditions at specific control points (if needed)

Step 4: Contact force calculating (for contact points only).

1. Calculate the normal vector from Eq. (14)

2. Calculate the center-of-mass velocity using Eq. (10)

3. Check the contact condition in Eq. (9)

If two body are in contact, continue sub-step 4 and 5 . If not, move to Step 5.

4. Compute contact force at contact control points $I$ : $f_{I}^{\text {contract }, i, t}=\frac{m_{I}^{i, t}}{\triangle t^{i}}\left(v_{I}^{c m, t}-v_{I}^{i, t}\right)$

5. Correct the control point momentums: $f_{I}^{\text {correct }, i, t}=f_{I}^{i, t+\triangle t}+f_{I}^{\text {contract }, i, t}$

Step 5: Mapping data from control points to particles 1. Update particle velocities: $v_{p}^{i, t+\Delta t}=v_{p}^{i, t}+$ $\frac{\triangle t}{m_{I}^{i, t}} \sum_{I} N_{I}\left(x_{p}^{t}\right)\left(f_{I}^{i, t}+f_{I}^{\text {contact }, i, t}\right)$

2. Update particle positions: $x_{p}^{i, t+\Delta t}=x_{p}^{i, t}+$ $\frac{\triangle t}{m_{I}^{i, t}} \sum_{I} N_{I}\left(x_{p}^{t}\right) p_{I}^{\text {correct }, i, t+\triangle t}$

3. For MUSL only, get control point velocities: $v_{p}^{i, t+\triangle t}=p_{I}^{\text {correct }, i, t+\triangle t} / m_{I}^{i, t}$

4. Compute particle gradient velocity: $L_{p}^{i, t+\triangle t}=$ $\sum_{I} \nabla N_{I}\left(x_{p}^{i, t}\right) v_{I}^{i, t+\triangle t}$

5. Update particle gradient deformation tensor: $F_{p}^{i, t+\triangle t}=\left(I+L_{p}^{i, t+\triangle t} \triangle t\right) F_{p}^{i, t}$

6. Update particle volume: $V_{p}^{i, t+\triangle t}=$ $\operatorname{det}\left(F_{p}^{i, t+\triangle t}\right) V_{p}^{i, 0}$ 
7. Compute strain increment: $\triangle e_{p}=$ $\operatorname{sym}\left(L_{p}^{i, t+\triangle t}\right) \triangle t$, then compute the stress increment $\triangle \sigma_{p}$.

8. Update particle stresses: $\sigma_{p}^{i, t+\triangle t}=\sigma_{p}^{i, t}+\triangle \sigma_{p}$

Then, reset the computational grid and move to the next time step.

\section{RESULTS}

Two numerical examples are presented in this section, particularly:

- Collision of two circular disks.

- Collision of a circular disk onto a rectangular block.

The first example investigates the contact of two circular surface with the same material. The second example studies the contact of a soft circular surface and hard flat surface.

To validate the results from these two examples, corresponding FEM models are created from ABAQUS software. FEM model is prepared with very fine mesh and set up with the same parameters and initial conditions as MPM (and BSMPM) model.

\section{Collision of two circular disks}

The problem is shown in Figure 5, two elastic disks with the same radius $R=0.2 \mathrm{~m}$ and the thickness is one unit. The material properties used in this problem are: Young's modulus $E=1000 \mathrm{~Pa}$, Poisson ratio $v=0.3$, and the mass density $\rho_{0}=1000 \mathrm{~kg} / \mathrm{m}^{3}$. The coordinate of the center of the lower-left disk is $(0.2,0.2)$, the upper-right disk is $(0.7,0.7)$, two disks are in a square domain of size $0.9 \times 0.9 \mathrm{~m}^{2}$. The initial velocities of the particles $v=(0.1,0.1) \mathrm{m} / \mathrm{s}$, for the upper-right disk, the velocities of the particles are set to $v_{p}=-v$ and for the lower-left $v_{p}=v$.

The computational domain is discretized into $40 \times 40$ knot spans. Each computational cell has 9 particles. The original MPM with Lagrange basis and quadratic $\operatorname{BSMPM}(d=2)$ are concerned in this example.

The time step for this simulation is chosen as $\Delta t=$ $0.001 s$, the total simulation time is $3 s$. So, there is 3000 steps in this simulation.

The kinetic and strain energy obtained from BSMPM and FEM is shown in Figure 6. Kinetic energy in BSMPM decreases earlier than the result from FEM and strain energy in BSMPM increases earlier. This is reasonable for the contact in BSMPM algorithm and will be explained in the comment of Figure 7 . The value of kinetic energy in both case are the same, while the strain energy in BSMPM is lower than FEM. Both case are in frictionless contact, so there is no energy

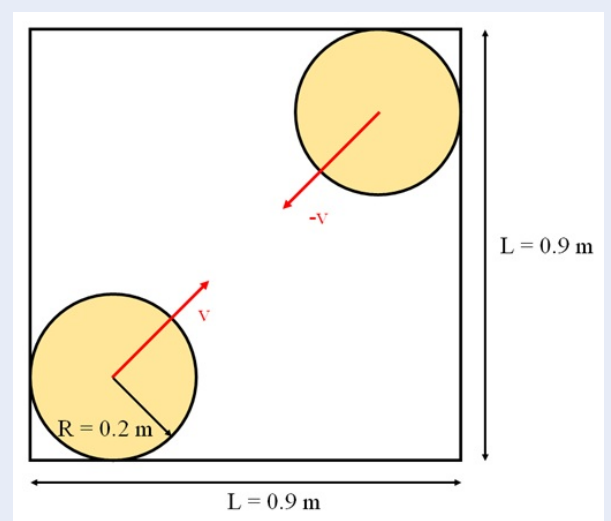

Figure 5: Impact of two circular disks.

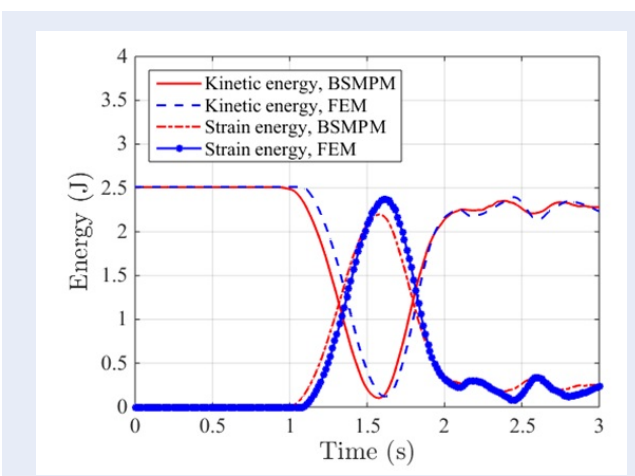

Figure 6: Kinetic and strain energy.

loss from friction, the strain energy loss in BSMPM is caused by other error factors.

The variation of contact force during the impact process is shown in Figure 7. The FEM model used to simulate this problem has 3288 nodes. The results from MPM and BSMPM show that the impact of two bodies occurs earlier than the result in FEM as mentioned before. This is because the contact force in MPM is computed in the node of the computational grid (or control point in BSMPM), not in the particle of the body, so when two bodies approach the contact region and have the same control points, the contact is detected immediately although two bodies have not touched each other yet. In FEM, the contact is only detected when two bodies touch each other, so the contact force obtained in FEM is later than MPM.

The contact force obtained from BSMPM using higher order B-spline functions also shows the smooth curve compared to the MPM and FEM.

Figure 8 shows the von-Mises stress field during the impact process of two disks using the BSMPM. In detail, two disks approaching each other in Figure 8 (a), 


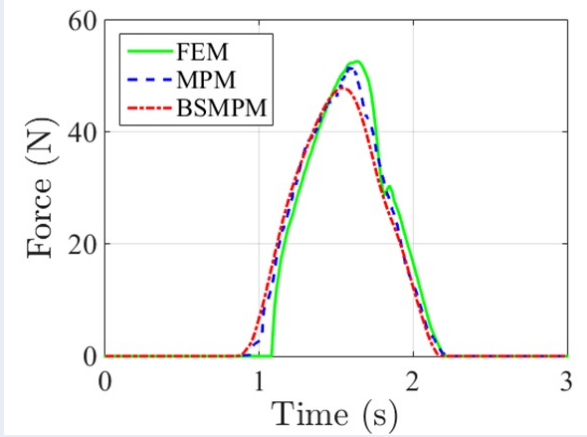

Figure 7: Impact force obtained from FEM, MPM and BSMPM $(d=2)$ then two disks touch each other as shown in Figure 8 (b), two disks deform during the impact as shown in Figure 8 (c) and then bounce back in Figure 8 (d). After impact, two disks move far away as shown inFigure $8(\mathrm{e})$.

\section{Collision of a circular disk onto a rectangu- lar block}

In this example, a circular disk collides onto a stiffer rectangular block, as shown in Figure 9.

The radius of the circular disk is $R=0.2 \mathrm{~m}$, and the thickness is one unit. The material properties used for circular disk are: Young's modulus $E_{1}=1000 \mathrm{~Pa}$, Poisson ratio $v_{1}=0.3$, and the mass density $\rho_{1}=$ $1000 \mathrm{~kg} / \mathrm{m}^{3}$. The rectangular block is made from stiffer material with Young's modulus $E_{2}=10^{6} \mathrm{~Pa}$, Poisson ratio $v_{2}=0.3$, and the mass density $\rho_{1}=$ $5000 \mathrm{~kg} / \mathrm{m}^{3}$, the rectangular size is $1 \times 0.2 \mathrm{~m}^{2}$. Distance between the center of the circular disk to the top of rectangular block is $0.3 \mathrm{~m}$. The computational domain is a square with dimension of $1.2 \times 1.2 \mathrm{~m}^{2}$. The initial velocity of the disk is $v=(0,-0.2) \mathrm{m} / \mathrm{s}$. In this simulation, the gravitational acceleration is ignored.

The computational domain is discretized into a set of $60 \times 60$ knot spans. Each cell has 9 particles. The nodes (or control points) on the bottom line of the rectangular is fixed in two direction $x$ and $y$.

The time step size is chosen as $\triangle t=0.001 \mathrm{~s}$, and the total simulation time is $2 \mathrm{~s}$. So, there is 2000 steps in this simulation.

The contact force obtained in this example also shows the similarity to the conclusions from the previous example. Figure 10 also shows that the impact occurs earlier in BSMPM, because BSMPM has more control points (nodes) than MPM so the contact is detected earlier. Similarly to the previous example, the contact force in BSMPM is smoother than the curve from

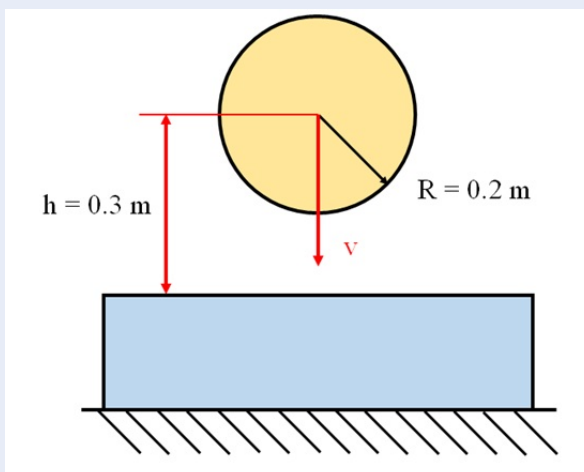

Figure 9: A circular disk collides with a rectangular block.

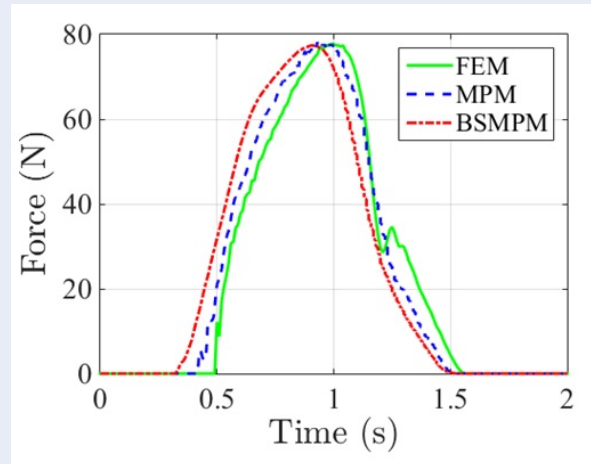

Figure 10: Impact force of example 5.2 obtained from FEM, MPM and BSMPM ( $d=2)$

FEM and MPM.

Figure 11 shows the collision of two objects, the vonMises stress field and maximum stress field are presented.

To investigate the convergence of BSMPM and MPM, the computational domain with a set of $60 \times 60 \mathrm{knot}$ spans is retained. Different numbers of particles per cell (PPC) 4, 9 and 16 are analyzed. Figure 12 shows the total energy of the system respect to time. From the initial conditions, the total energy can be computed as $\rho \pi R^{2} t v^{2} / 2=2.512 \mathrm{~J}$ and plotted by the black line in the figure. As shown in Figure 12, the case of MPM with PPC $=4$ gives a very large deviation, and when $\mathrm{PPC}=9$, the result is significantly improved. In the case of BSMPM, there are no significant deviations and the results are slightly improved when increasing PPC.

\section{DISCUSSIONS}

As present in Section 3, there is a slight difference in the results of MPM, BSMPM and FEM. The mag- 

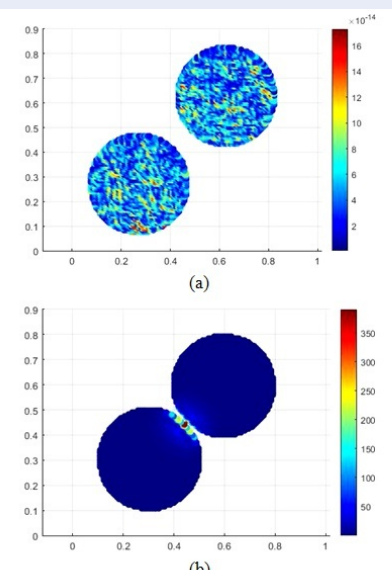

(b)
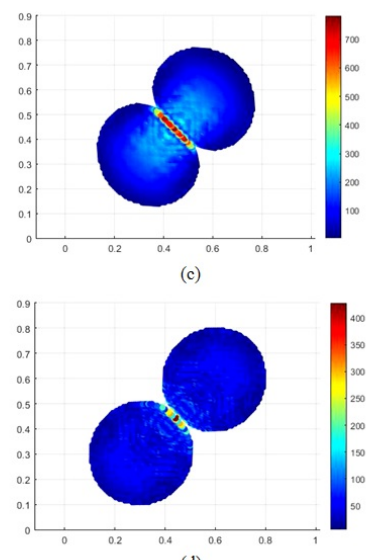

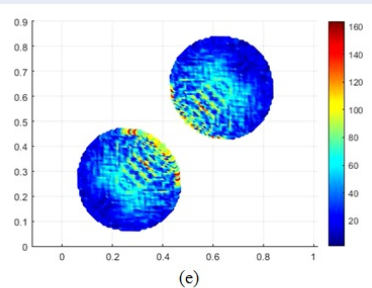

(e)

Figure 8: Impact of two circular disks.

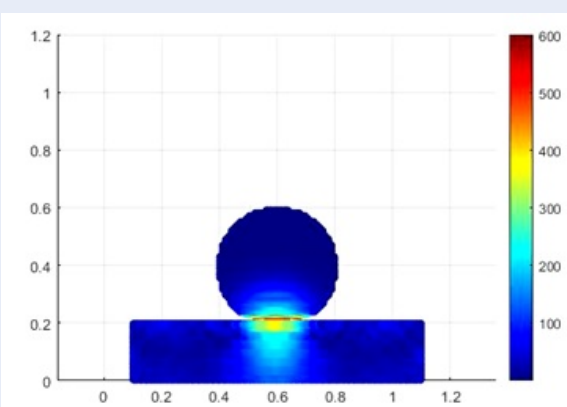

(a)

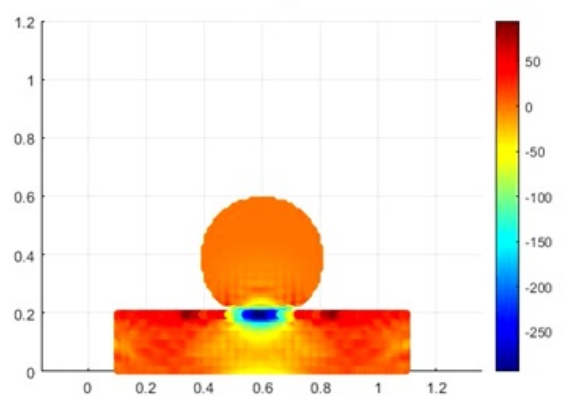

(b)

Figure 11: Circular disk deforms during the impact process onto a stiffer surface. (a) von-Mises stress and (b) Maximum stress.

nitude of the contact force in the three methods is the same, but the impact occurs earlier in MPM and BSMPM. This is because the contact force in MPM is computed in the node of the computational grid (or control point in BSMPM), not in the discrete particle of the object, so when two objects approach the contact region and have same the grid node (control points), the contact is detected immediately although

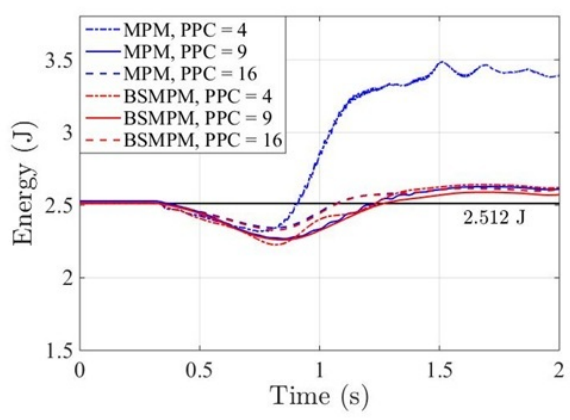

Figure 12: Energy of the system respect to time with different number of particles per cell.

two objects have not touched each other yet, there is still a gap. And because BSMPM uses higher-order shape functions, so the BSMPM has more control points (grid node) than MPM, the contact is therefore detected earlier. Moreover, if the contact algorithm is not used in MPM, the non-slip contact can still be determined automatically when two objects have the same grid node. In FEM, the contact is only detected when two objects touch each other (or even penetrate into each other), so the contact force obtained in FEM is later than MPM and BSMPM.

\section{CONCLUSIONS}

The contact algorithm has been successfully modified and applied into the BSMPM. The contact force obtained from this research is compared to FEM. A slight difference in the result is observed, this is because the contact force is calculated at the control point in the computational grid instead of the discrete 
particles. This is an inherent property of the MPM algorithm, so it is inevitable. More study on the contact algorithm need to be done to overcome this disadvantage and improve the accuracy of the method.

\section{ACKNOWLEDGMENT}

This research is funded by Ho Chi Minh City University of Technology - VNU-HCM, under grant number T-KHUD-2020-47. We acknowledge the support of time and facilities from Ho Chi Minh City University of Technology (HCMUT), VNU-HCM for this study.

\section{ABBREVIATIONS}

BSMPM: B-spline Material Point Method

FEM: Finite Element Method

MPM: Material Point Method

MUSL: Modified Update Stress Last

\section{CONFLICT OF INTEREST}

Group of authors declare that this manuscript is original, has not been published before and there is no conflict of interest in publishing the paper.

\section{AUTHOR CONTRIBUTION}

Vay Siu Lo is work as the chief developer of the method and the manuscript editor.

Nha Thanh Nguyen and Minh Ngoc Nguyen take part in the work of gathering data and checking the numerical results.

Thien Tich Truong is the supervisor of the group, he also contributes ideas for the proposed method.

\section{REFERENCES}

1. Zhang X, Chen Z, Liu Y. The Material Point Method A Continuum-Based Particle Method for Extreme Loading Cases. Elsevier. 2017;Available from: https://doi.org/10.1016/ B978-0-12-407716-4.00003-X.

2. Tielen R. High order material point method. master dissertation, Delft University of Technology, Delft. 2016;

3. Jassim I, Hamad F, Vermeer P. Dynamic material point method with applications in geomechanics. Stuttgart University, Germany. 2011;.

4. Nguyen VP. Material point method: basics and applications. Cardiff University, Department of Civil Engineering. 2014;

5. Wang $Y X$, et al. Response of multi-layered structure due to impact load using material point method. Engineering Mechanics. 2007:24(12):186-192

6. Hu WQ, Chen Z. Model-based simulation of the synergistic effects of blast and fragmentation on a concrete wall using the MPM," International Journal of Impact Engineering. 2006;32(12):2066-2096. Available from: https://doi.org/10. 1016/j.ijimpeng.2005.05.004.

7. Andersen S, Andersen L. Analysis of spatial interpolation in the material-point method. Computers and Structures. 2010;p. 506-518. Available from: https://doi.org/10.1016/j. compstruc.2010.01.004.
8. Nairn JA. Material point method calculations with explicit cracks. Computer Modeling in Engineering \& Sciences 2003;4:649-663.

9. II ARY, Sulsky D, Schreyer HL. Fluid-membrane interaction based on the material point method. International Journal for Numerical Methods in Engineering, vol. 48, pp. 901 924, 2000.;Available from: https://doi.org/10.1002/(SICI)10970207(20000630)48:6<901::AID-NME910>3.0.CO;2-T.

10. Badenhagen SG, Kober EM. The generalized interpolation material point method. Computer Modeling in Engineering \& Science. 2004;5(6):477-495.

11. Steffen $M$, et al. Examination and analysis of implementation choices within the material point method (MPM). Computer Modeling in Engineering \& Science. 2008;31(2):107-127.

12. Sadeghirad A, Brannon RM, Burghardt J. A convected particle domain interpolation technique to extend applicability of the material point method for problems involving massive deformations. International Journal for Numerical Methods in Engineering. 2011;86(12):1435-1456. Available from: https://doi.org/10.1002/nme.3110.

13. Zhang DZ, Ma X, Giguere P. Material Point Method enhanced by modified gradienet of shape function. Journal of Computational Physics. 2011;230(16):6379-6398. Available from: https: //doi.org/10.1016/j.jcp.2011.04.032.

14. Steffen M. Examination and Analysis of Implementation Choices within the Material Point Method (MPM). Computer Modellin in Engineering and Sciences. 2008;31(2):107-127.

15. Gan Y, et al. Enhancement of the material point method using B-spline basis functions. Numerical Methods in Engineering. 2017;113(3):411-431. Available from: https://doi.org/10.1002/ nme.5620.

16. Wobbes E, Moller M, Galavi V, Vuik C. Conservative Taylor Least Squares reconstruction with application to material point methods. International Journal for Numerical Methods in Engineering. 2018;117(3):271-290. Available from: https: //doi.org/10.1002/nme.5956.

17. II ARY, Sulsky D, Schreyer HL. The material point method for simulation of thin membranes. International Journal for Numerical Methods in Engineering. 1999;44(10):14291456. Available from: https://doi.org/10.1002/(SICI)10970207(19990410)44:10<1429::AID-NME536>3.0.CO;2-4.

18. Bardenhagen SG, et al. An improved contact algorithm for the material point method and application to stress propagation in granular material. Computer Modeling in Engineering and Sciences. 2001;2(4):509-522.

19. Hu W, Chen Z. A multi-mesh MPM for simulating the meshing process of spur gears. Computers and Structures. 2003;81(20):1991-2002. Available from: https://doi.org/10. 1016/S0045-7949(03)00260-8.

20. Huang $P$, Zhang $X$, Ma S, Huang X. Contact algorithms for the material point method in impact and penetration simulation. International journal for numerical methods in engineering 2010;85(4):498-517. Available from: https://doi.org/10.1002/ nme.2981.

21. Nairn JA. Modeling imperfect interfaces in the material point method using multimaterial methods. Computer Modeling in Engineering and Science. 2013;92(3):271-299. Available from: https://doi.org/10.32604/cmes.2013.092.271.

22. Ma J, Wang D, Randolph MF. A new contact algorithm in the material point method for geotechnical simulations. International Journal for Numerical and Analytical Methods in Geomechanics. 2014;38(11):1197-1210. Available from: https: //doi.org/10.1002/nag.2266.

23. Nguyen VP. Material point method: basis and application 2014;Available from: https://researchgate.net/publication/ 262415477_Material_point_method_basics_and_applications. 


\title{
Phân tích lực va chạm bằng phương pháp Điểm vật liệu sử dụng hàm dạng B-spline
}

\author{
Lồ Sìu Vẫy ${ }^{1,2, *}$, Nguyễn Thanh Nhã ${ }^{1,2}$, Nguyễn Ngọc Minh ${ }^{1,2}$, Trương Tích Thiện ${ }^{1,2, *}$
}

${ }^{1}$ Bộ môn Cơ kỹ thuật, Khoa Khoa học üng dung, Trường Đại học Bách Khoa TP.HCM, Việt Nam

${ }^{2} Đ a ̣ i$ học Quốc gia Thành phố Hồ Chí Minh, Việt Nam

Liên hệ

Lồ Sìu Vẫy, Bộ môn Cơ kỹ thuật, Khoa Khoa học ứng dụng, Trường Đại học Bách Khoa TP.HCM, Việt Nam

Đại học Quốc gia Thành phố Hồ Chí Minh, Việt Nam

Email: losiuvay@hcmut.edu.vn

Liên hệ

Trương Tích Thiện, Bộ môn Cơ kỹ thuật, Khoa Khoa học úng dụng, Trường Đại học Bách Khoa TP.HCM, Việt Nam

Đại học Quốc gia Thành phố Hồ Chí Minh, Việt Nam

Email: tttruong@hcmut.edu.vn

Lịch sử

- Ngày nhận: 18-11-2020

- Ngày chấp nhận: 11-3-2021

- Ngày đăng: 30-3-2021

DOI : 10.32508/stdjet.v4i1.794

Check for updates

\section{TÓM TẮT}

Trong giải thuật MPM, các điểm vật liệu được xây dựng trong một trường vận tốc đơn trị nên sự tương tác/tiếp xúc không trượt giữa các vật thể tự động được thỏa mãn mà không cần sử dụng giải thuật tiếp xúc. Tuy nhiên, trong một số bài toán va chạm và đâm xuyên, điều kiện tiếp xúc không trượt của MPM là không phù hợp và thậm chí có thể đem lại kết quả không hợp lý, vì vậy cần phải thêm vào MPM một giải thuật tiếp xúc thích hợp để giải quyết hạn chế này. Trong bài báo này, sự thay đổi của lực tiếp xúc theo thời gian gây ra do va chạm được nghiên cứu. MPM sủ dụng hàm dạng Lagrange nên gây ra hiện tượng "cell-crossing" khi một điểm vật liệu di chuyển tù một ô này sang ô khác. Bản chất của hiện tượng này là do sự không liên tục của gradient của hàm dạng tuyến tính. Độ chính xác của kết quả vì thế cũng bị ảnh hưởng. Trong nghiên cứu này, MPM với hàm B-spline bậc cao được sử dụng để tránh hiện tượng "cell-crossing". BSMPM sử dụng hàm dạng B-spline bậc cao để đảm bảo rằng đạo hàm của hàm dạng là liên tục, do đó giảm được sai số. Giải thuật của MPM và BSMPM có một số khác biệt trong việc xác định lưới tính toán. Vi vậy, giải thuật tiếp xúc của MPM cần được hiệu chỉnh phù hợp để có thể sử dụng cho BSMPM. Mục đích của nghiên cứu này là nhằm xây dựng một giải thuật tiếp xúc phù hợp cho BSMPM và sử dụng nó để khảo sát lực tiếp xúc gây ra bởi va chạm. Một vài ví dụ số được trình bày trong bài báo này, sự va chạm của hai đĩa tròn đàn hồi và sự va chạm của một đĩa tròn mềm vào một khối chũ nhật cứng hơn. Các kết quả về lực tiếp xúc thu được đều được so sánh với các kết quả từ phần tử hữu hạn và đều phù hợp, sự bảo toàn năng lượng của hệ cũng được xem xét.

Từ khoá: BSMPM, giải thuật tiếp xúc, lực tiếp xúc, va chạm, MPM
Trích dẫn bài báo này: Vẫy L S, Nhã N T, Minh N N, Thiện T T. Phân tích lực va chạm bằng phương pháp Điểm vật liệu sử dụng hàm dạng B-spline. Sci. Tech. Dev. J. - Eng. Tech.; 4(1):722-730 